\title{
Carboxypeptidase $\mathbf{N}$ and Creatine Kinase-MB Isoforms in Acute Myocardial Infarction
}

\author{
Martina Zaninotto ${ }^{1}$ Sara Altinier ${ }^{2}$, Mattia Lachin ${ }^{1}$ and Mario Plebani ${ }^{1,2}$ \\ 1 Servizio di Medicina di Laboratorio, Azienda Ospedaliera di Padova, Padova, Italy \\ 2 Centro Regionale di Ricerca Biomedica, Castelfranco Veneto (TV), Italy
}

Summary: The aims of our study were to evaluate the plasma carboxypeptidase $\mathrm{N}$ activity in normal subjects and in patients with acute myocardial infarction and to delineate its relationship with creatine kinase-MB isoforms in monitoring of acute myocardial infarction, carboxypeptidase $\mathrm{N}$ being the major determinant of creatine kinase isoform conversion in plasma. The study was carried out in 34 healthy subjects and 19 patients with acute myocardial infarction diagnosed according to the World Health Organization (WHO) criteria in which the blood samples were collected immediately upon admission to the coronary care unit (median time 3.5 hours), every 4 to 6 hours for 24 hours, and every 12 hours until the third day post admission. Carboxypeptidase $\mathrm{N}$ activity, total creatine kinase, creatine kinase-MB mass concentration and creatine kinase-MB isoforms were determined in each sample from acute myocardial infarction patients, whereas only carboxypeptidase $\mathrm{N}$ and total creatine kinase activities were assayed in samples from healthy subjects. The results showed a high variability in carboxypeptidase $\mathrm{N}$ values among healthy subjects (median $=220 \mathrm{U} / \mathrm{l}$; interquartile range $=190-247 \mathrm{U} / \mathrm{l}$ ) and in the first available samples from acute myocardial infarction patients (median $=213 \mathrm{U} / \mathrm{l}$; interquartile range $=197-234 \mathrm{U} / \mathrm{l}$ ) without significant differences between groups and without a correlation between carboxypeptidase $\mathrm{N}$ and creatine kinase activities either in healthy subjects or in acute myocardial infarction patients; in the latter group, however, a significant correlation $(p<0.01)$ with creatine kinase-MB calculated on all samples, was observed. In acute myocardial infarction patients carboxypeptidase $\mathrm{N}$ showed time-related variations, reaching the highest levels about $48 \mathrm{~h}$ after onset of chest pain. A statistically significant difference in carboxypeptidase $N$ values $(p=0.0001)$ was found before and after creatine kinase-MB peak values as well as before and after $\mathrm{MB}_{2} / \mathrm{MB}_{1}$ normalization. Worthy of note is the finding that in two acute myocardial infarction patients presenting $\mathrm{MB}_{2} / \mathrm{MB}_{1}$ ratios lower than the cutoff value (1.5) throughout the period of observation, the baseline values for carboxypeptidase $\mathrm{N}$ were higher than in other patients studied. Our results suggest that the increase of carboxypeptidase $\mathrm{N}$ activity after infarction could be induced by an increase in endogenous substrate concentrations, in particular creatine kinase-MB released from damaged myocardium. Furthermore, high baseline levels of carboxypeptidase $\mathrm{N}$ will reduce the diagnosis efficiency of creatine kinase-MB isoforms in the diagnosis of acute myocardial infarction.

\section{Introduction}

The creatine kinase $\left.{ }^{1}\right)-\mathrm{MB}$ isoforms and, in particular, the $\mathrm{MB}_{2}$ (tissue isoform containing $\mathrm{C}$-terminal lysine) to $\mathrm{MB}_{1}$ (circulating des-lysine isoform) ratio is a sensitive and specific marker for the early diagnosis of acute

\footnotetext{
1) Enzymes:

Carboxypeptidase N (arginine carboxypeptidase, EC 3.4.17.3);

Creatine kinase (ATP : creatine N-phosphotransferase, EC 2.7.3.2).

2) Remark of the Managing Editor:

The absorption coefficient at $336 \mathrm{~nm}$ is given by 1 .c. (15) with $\Delta \varepsilon=-1300 \mathrm{M}^{-1} \mathrm{~cm}^{-1}$, corresponding to $130 \mathrm{~m}^{2} \times \mathrm{mol}^{-1}$. In 1.c. (13) "an absorption coefficient of $0.13 \mathrm{~L} \cdot \mathrm{nmol}^{-1} \cdot \mathrm{min}^{-1}$ " is given. This was repeated by Skidgel RA, Erdös EG. Carboxypeptidase $\mathrm{N}$ (arginine carboxypeptidase) peptidyl- $L$-arginine hydrolase, EC 3.4.17.3. In: Bergmeyer HU, editor. Methods of enzymatic analysis. 3rd English ed., vol. V. Weinheim: Verlag Chemie, 1988:60-72. In the latter two publications it should read: 0.131 $\times \mathrm{mmol}^{-1} \times \mathrm{mm}^{-1}$, also corresponding to $130 \mathrm{~m}^{2} \times \mathrm{mol}^{-1}$.
}

myocardial infarction as well as for the assessment of coronary reperfusion after thrombolytic therapy (1-4). Moreover, now that a real-time, fully-automated method is available for their measurement, this assay is also an interesting tool for the early diagnosis of acute myocardial infarction in emergency $(5,6)$. Previous studies $(7-9)$ indicated that the tissue creatine kinase- $\mathrm{MB}_{2}$ isoform released from the damaged myocardium is converted in the blood to creatine kinase- $\mathrm{MB}_{1}$ by carboxypeptidase $\mathrm{N}^{1}$ ), an enzyme synthesized in the liver and secreted as a $M_{\mathrm{r}}=280000$ tetramer and which is known to be an important inactivator of peptide hormones such as bradykinin and anaphylatoxins. Although the enzyme appears to be present in all humans, its levels in plasma vary considerably among subjects. In normal subjects, in fact, up to a threefold variation in enzyme activity has been observed; during pregnancy and during the 
course of certain types of cancer, elevated enzyme concentrations have been reported while low concentrations have been observed in patients with cirrhosis of the liver $(10,11)$. The reported variability in carboxypeptidase $\mathrm{N}$ activities may therefore be important in the use of the creatine kinase-MB isoform ratio for the diagnosis of myocardial infarction: in fact, the sensitivity and the diagnostic accuracy of isoform analysis for the detection of infarction will likely depend, in part, on the rate of conversion of isoforms in plasma (12). However, despite some evidence correlating variations of carboxypeptidase $\mathrm{N}$ and creatine kinase-MM in acute myocardial infarction (13), no data exist on the relationship between plasma carboxypeptidase $\mathrm{N}$ activity and creatine kinaseMB isoforms in acute myocardial infarction.

The aim of this study was to delineate the relationship between creatine kinase-MB isoforms and carboxypeptidase $\mathrm{N}$ activity in patients with acute myocardial infarction.

\section{Materials and Methods}

\section{Subjects and blood collection}

The study was carried out on 34 healthy subjects ( 14 males and 20 females, aged 23 to 55 years) from the laboratory staff and 19 patients (12 men and 7 women, aged 46 to 74 years) with acute myocardial infarction diagnosed according to WHO criteria (characteristic chest pain, unequivocal ECG changes and serial increases in creatine kinase and creatine kinase-MB mass concentration with peak values twice the upper limit of the reference interval); 14 had Q-wave and 5 non-Q-wave indicated infarctions. The patients were admitted to the coronary care unit within 9 hours after the onset of symptoms (range $0.5-9 \mathrm{~h}$; median $3.5 \mathrm{~h}$ ); 12 underwent thrombolytic treatment while 7 were not treated depending on clinical circumstances; 10 were classified as reperfused on the basis of their clinical pictures (symptoms resolved rapidly, ST-segment changes improved, presence of reperfusion arrhythmias) (14). Blood samples were collected from patients immediately upon admission to the coronary care unit and every 4 to 6 hours thereafter for 24 hours and then every 12 hours until the third day of hospitalization. All patients gave their informed consent for extra blood samples to be drawn. Carboxypeptidase $\mathrm{N}$ activity, total creatine kinase, creatine kinase-MB mass concentration and creatine kinase-MB isoforms were determined in each sample from acute myocardial infarction patients, whereas only carboxypeptidase $\mathrm{N}$ and total creatine kinase activities were assayed in samples from the healthy subjects.

Venous blood samples for the measurement of creatine kinase, creatine kinase-MB mass and carboxypeptidase $\mathrm{N}$ were drawn in lithium heparinate-containing tubes, centrifuged at $2000 \mathrm{~g}$ for $15 \mathrm{~min}$ utes and analyzed immediately. Samples for creatine kinase isoform determination were collected in tubes containing ethylene glycol bis ( $\beta$-aminoethyl ether)-N,N, $\mathrm{N}^{\prime}, \mathrm{N}^{\prime}$ tetracetic acid (EGTA, final concentration $30 \mathrm{mmol} / \mathrm{l}$ ) and 2-mercaptoethanol (final concentration $10 \mathrm{mmol} / \mathrm{l}$ ) to inhibit carboxypeptidase $\mathrm{N}$-mediated isoform conversion after blood collection, and the EGTA-plasma was stored at $-20^{\circ} \mathrm{C}$ until analysis (1).

\section{Methods}

\section{Carboxypeptidase $N$ activity}

Spectrophotometric assay at $37^{\circ} \mathrm{C}$ using furylacryloyl-alanyl-lysine as the substrate (Sigma Diagnostic, Milano, Italy) according to Plummer \& Kimmel (15) was used to measure carboxypeptidase $\mathrm{N}$ activity, $40 \mu \mathrm{l}$ of sample being added to $3 \mathrm{ml}$ of the reaction buffer $(0.05 \mathrm{~mol} / 1 \mathrm{HEPES}, \mathrm{pH} 7.75,0.25 \mathrm{~mol} / 1 \mathrm{NaCl})$ containing $0.5 \mathrm{mmol} / 1$ of substrate, previously equilibrated at $37^{\circ} \mathrm{C}$. Absorbance was measured at $336 \mathrm{~nm}$ over a 6 minute period; the enzyme activities, calculated using a conventional method with a molar absorption coefficient ${ }^{2}$ ) of $130 \mathrm{~m}^{2} \times \mathrm{mol}^{-1}$ (13), were expressed as $\mathrm{U} / 1(1 \mathrm{U}=$ amount of enzyme hydrolyzing $1 \mu \mathrm{mol}$ of furylacryloyl-alanyl-lysine per minute).

The within-day coefficient of variation $(n=11)$ was $4.8 \%$ at a mean value of $217 \mathrm{U} / 1$ and $3.6 \%$ at $251 \mathrm{U} / 1$. In the same sera, between-day coefficients of variation of $7.5 \%$ and $6.3 \%$ respectively were obtained.

\section{Total creatine kinase catalytic activity concentration}

The catalytic concentration of creatine kinase was determined at $37^{\circ} \mathrm{C}$ (Bracco, Milano, Italy) according to the method recommended by the IFCC (16). The upper reference limits were $>160$ $\mathrm{U} / 1$ for females and $>190 \mathrm{U} / \mathrm{l}$ for males.

\section{Creatine kinase-MB mass concentration}

The mass concentration of creatine kinase-MB was measured using a commercially available fluorometric enzyme immunoassay (Stratus CK-MB; Baxter Dade, Milano, Italy) with a sensitivity of 0.4 $\mu \mathrm{g} / \mathrm{l}$. The upper reference limit was $5 \mu \mathrm{g} / \mathrm{l}$.

\section{Creatine kinase-MB isoforms}

Using high-voltage electrophoresis on agarose gels with the automated REP/EDC system (Helena Laboratories, Milano, Italy) creatine kinase-MB isoforms were separated, and then detected by fluorescence densitometry. This procedure also enables the separation of creatine kinase-MM isoforms, but only the more specific cardiac creatine kinase-MB isoforms were considered in our study, two creatine kinase-MB isoforms being separated with this procedure: according to their electrophoretic mobilities, isoform creatine kinase- $\mathrm{MB}_{2}$ is the most cathodic band while creatine kinase$\mathrm{MB}_{1}$ is the fastest moving, most anodic band in the creatine kinase series.

The within-run and between-run precision (CVs) calculated in a sample with $\mathrm{MB}_{2} / \mathrm{MB}_{1}$ ratio of 0.93 and $\mathrm{MB}_{2}$ activity of $5.8 \mathrm{U} / 1$ were $9.1 \%$ and $11.6 \%$ respectively. The minimum MB activity for isoform analysis using this procedure was $4 \pm 1 \mathrm{U} / \mathrm{l}$. The upper reference limit for the $\mathrm{MB}_{2} / \mathrm{MB}_{1}$ ratio was 1.5 (5).

\section{Statistics and calculation}

Medians and percentiles were calculated to described continuous variables. Two-way unpaired t-tests were used for between-group comparison of the results, while one-way paired t-tests were used to compare the results from acute myocardial infarction patients: $p$ values $<0.05$ were considered to indicate statistical significance.

\section{Results}

The carboxypeptidase $\mathrm{N}$ activities in plasma of normal subjects and in the first blood sample of patients with myocardial infarction collected $3.5 \mathrm{~h}$ (median) after the onset of chest pain show a high variability over a twofold range among subjects, without a significant difference between controls (median $=220 \mathrm{U} / 1$; interquartile range $=190-247 \mathrm{U} / \mathrm{l}$ ) and acute myocardial infarction patients (median $=213 \mathrm{U} / \mathrm{l}$; interquartile range $=197-$ $234 \mathrm{U} / 1)$.

The pattern of carboxypeptidase $\mathrm{N}$ values in patients with myocardial infarction (fig. 1) shows time-related variations, the highest levels (ranging from 10 to $72 \%$ 


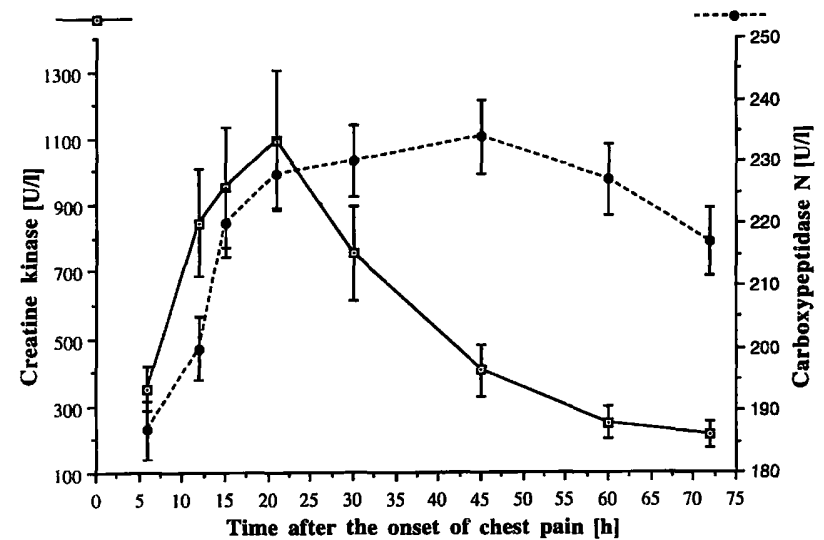

Fig. 1 Time-related variations of carboxypeptidase $\mathrm{N}$ and total creatine kinase in patients with acute myocardial infarction (mean values $\pm \mathrm{SE}$ ).

to initial values) being reached about 48 hours after the onset of chest pain, and maintained for more than 60 hours. The increased values in carboxypeptidase $\mathrm{N}$ concentrations following infarction and the maximum level therefore occurred in each patient later also in respect to total creatine kinase, the last marker of acute myocardial infarction to be considered in our study. Furthermore, no correlation was found between carboxypeptidase $\mathrm{N}$ and total creatine kinase values either in healthy subjects ( $n=34 ; r=0.051, p=0.774)$ or in all samples of acute myocardial infarction patients $(\mathrm{n}=171 ; \mathrm{r}=0.346$, $\mathrm{p}=0.061$, while in the latter group a significant correlation between carboxypeptidase $\mathrm{N}$ and creatine kinaseMB concentrations $(r=0.479 ; p<0.01)$ was obtained.

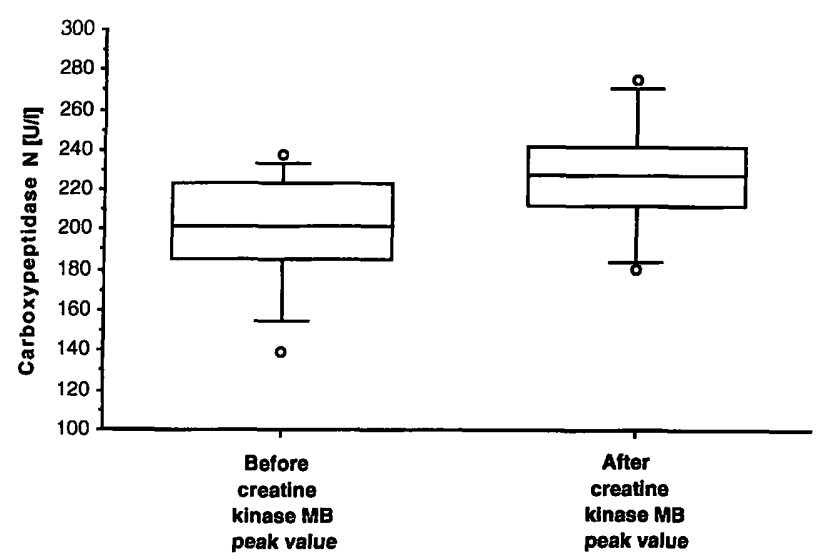

Fig. 2 Distribution of carboxypeptidase $\mathrm{N}$ values from patients with acute myocardial infarction in relation to creatine kinase-MB peak concentrations.

Figure 2 shows the relationship between carboxypeptidase $\mathrm{N}$ values and creatine kinase MB mass concentration (median time to peak concentration $15 \mathrm{~h}$; interquartile range $10-26 \mathrm{~h}$ ) in patients studied. The reported results show that the values of carboxypeptidase $\mathrm{N}$ obtained from each patient in the sample collected before creatine kinase-MB peak concentrations (median $=201$ $\mathrm{U} / 1$, interquartile range: $184-223 \mathrm{U} / 1$ ), were signifi- cantly lower $(p=0.0001)$ than those obtained from the samples collected after creatine kinase-MB peak values (median $=227 \mathrm{U} / 1$, interquartile range: $211-242 \mathrm{U} / 1$ ). In the same patients the relationship between carboxypeptidase $\mathrm{N}$ and the $\mathrm{MB}_{2} / \mathrm{MB}_{1}$ ratio shows, as expected, a statistically significant difference $(p=0.0001)$ between carboxypeptidase $\mathrm{N}$ values before (median $=184$ U/l, interquartile range: 171-201) and after (median $=209 \mathrm{U} / \mathrm{l}$, interquartile range: $203-243 \mathrm{U} / \mathrm{l}) \mathrm{MB}_{2} / \mathrm{MB}_{1}$

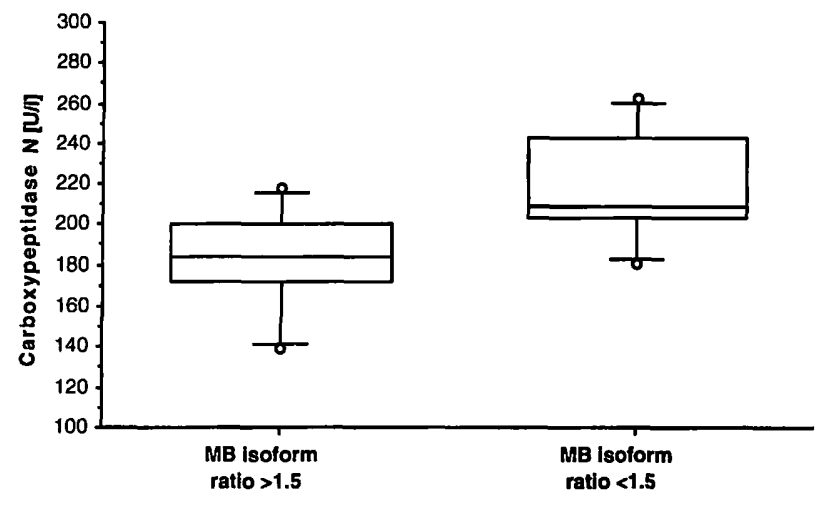

Fig. 3 Distribution of carboxypeptidase $\mathrm{N}$ values from patients with acute myocardial infarction in relation to the creatine kinaseMB isoform ratio.

normalization (fig. 3). However, in two out of the 19 acute myocardial infarction patients monitored in our study, the creatine kinase-MB isoform ratio was lower than the cutoff value $(\overline{\mathrm{x}} \pm \mathrm{SD}: 0.39 \pm 0.13$ and 0.51 \pm 0.12 respectively) throughout the period of observation. In these two patients the first blood samples were obtained shortly after the onset of chest pain (2.5 and 2.0 hours respectively), with creatine kinase-MB concentrations ranging from 6.3 to $246 \mu \mathrm{g} / 1$ and from 7.8 to $351 \mu \mathrm{g} / 1$ (baseline and peak values respectively). Worthy of note is the finding that in these patients the baseline carboxypeptidase $\mathrm{N}$ values $(222 \mathrm{U} / 1$ and $228 \mathrm{U} / 1$ respectively) were higher compared to those from patients $(\mathrm{n}=8)$ with similar hospital admission time $(2-3.5 \mathrm{~h})$ in which the median baseline value was $189 \mathrm{U} / 1$ (interquartile range: 174-206 U/1). These observations suggest that the baseline values of carboxypeptidase $\mathrm{N}$ acitivity in acute myocardial infarction patients were responsible for early conversion of tissue $\mathrm{MB}_{2}$ isoform into plasma $\mathrm{MB}_{1}$ isoform allowing an early shift of the $\mathrm{MB}_{2}$ / $\mathrm{MB}_{1}$ ratio.

\section{Discussion}

Analysis of isoforms of creatine kinase-MB in plasma was recently shown to enable the detection of acute myocardial infarction and of coronary recanalization very early after their onset, before a significant elevation in total creatine kinase activity and, in some cases, cre- 
atine kinase-MB (1-6). The sensitivity of isoform analysis results from the early release from the damaged myocardium of the tissue isoenzyme of $\mathrm{MB}\left(\mathrm{MB}_{2}\right)$, which is converted in plasma into an additional subform $\left(\mathrm{MB}_{1}\right)$ with a similar specific activity but different isoelectric point (isoforms). Thus, the release in plasma of a modest amount of creatine kinase- $\mathrm{MB}_{2}$ after myocardial infarction causes a prompt and marked increase in the $M B_{2}$ to $M_{1}$ ratio $(17,18,20-22)$.

Several studies have shown that carboxypeptidase $\mathrm{N}$ is the main factor accounting for isoform conversion in human plasma under physiological conditions $(7-11)$ and after myocardial infarction, elucidating in particular the relation between carboxypeptidase $\mathrm{N}$ activity in plasma and observed rates of creatine kinase-MM isoform conversion (13).

On the basis of these suggestions, the aim of our study was to ascertain the variations in plasma carboxypeptidase $\mathrm{N}$ activity in normal subjects and in patients undergoing acute myocardial infarction and to delineate its relationship with creatine kinase-MB isoforms. The carboxypeptidase $\mathrm{N}$ levels were assessed using a sensitive and specific method, showing good analytical performance, as previously demonstrated (15).

Time-related variations of carboxypeptidase $\mathrm{N}$ activity in patients with acute myocardial infarction were found with the highest level being reached about 48 hours after the onset of pain. In none of the subjects studied was a correlation observed between carboxypeptidase $\mathrm{N}$ and total creatine kinase values. However, a significant correlation between carboxypeptidase $\mathrm{N}$ and creatine kinase-MB concentrations has been found in patients with myocardial infarction, carboxypeptidase $\mathrm{N}$ values being significantly different in relation to creatine kinase-MB peak concentrations.

\section{References}

1. Puleo PR, Guadagno PA, Roberts R, Scheel MV, Marian AJ, Churchill D, et al. Early diagnosis of acute myocardial infarction based on assay for subforms of creatine kinase-MB. Circulation $1990 ; 82: 759-64$.

2. Abendschein DR. Rapid diagnosis of myocardial infarction and reperfusion by assay of plasma isoforms of creatine kinase isoenzymes. Clin Biochem 1990; 23:399-407.

3. Bhayana V, Cohoe S, Leung FY. Jablonsky G, Henderson AR. Diagnostic evaluation of creatine kinase- 2 mass and creatine kinase-3 and -2 isoform ratios in early diagnosis of acute myocardial infarction. Clin Chem 1993; 39:488-95.

4. Christenson RH, Ohman EM, Topol EJ, O'Hanesian MA, Sigmon $\mathrm{KN}$, Duh $\mathrm{SH}$, et al. Creatine kinase-MM and MB isoforms in patients receiving thrombolytic therapy and acute angiography. Clin Chem 1995; 41:844-52.

5. Puleo PR, Meyer D, Wathen C, Tawa CB, Wheeler S, Hamburg RJ, et al. Use of a rapid assay of subforms of creatine kinase-MB to diagnose or rule out acute myocardial infarction. N Engl J Med 1994; 331:561 -6.
These results suggest that the increase in carboxypeptidase $\mathrm{N}$ after infarction might be induced by the increase in endogenous substrate concentrations, in particular creatine kinase-MB, released from the damaged myocardium and emphasize the need of further studies for better understanding the behaviour of this enzymatic activity.

Moreover, our findings underline the relevance of carboxypeptidase $\mathrm{N}$ determination for the accurate diagnosis of acute myocardial infarction using the assay of creatine kinase-MB isoforms. In fact, two evaluated patients, who during monitoring had $\mathrm{MB}_{2}$ to $\mathrm{MB}_{1}$ ratios, lower than the cutoff value, had high baseline carboxypeptidase levels yielding false negative results. This evidence, in conjunction with the already described influence of low carboxypeptidase $\mathrm{N}$ levels in normal subjects leading to false positive results for the $\mathrm{MM}$ isoform ratio (13), emphasizes the need for caution in evaluating the creatine kinase-MB isoform results in acute myocardial infarction.

\section{Conclusion}

The determination of creatine kinase-MB isoforms in plasma provides considerable advantages for the early, non-invasive detection of acute myocardial infarction as well as for the evaluation of coronary recanalization. Nevertheless, findings made by us and by other authors $(12,13)$ indicate that the biological variations in carboxypeptidase $\mathrm{N}$ activity may be of importance in the clinical use of the creatine kinase-MB isoform ratio. Thus, the determination of carboxypeptidase $\mathrm{N}$ concentrations using a rapid and analytically accurate procedure may increase the specificity and the sensitivity of this test in the diagnosis of acute myocardial infarction.

6. Secchiero S, Altinier S, Zaninotto M, Lachin M, Plebani M. Evaluation of a new automated system for the determination of CK-MB isoforms. J Clin Lab Anal 1995; 9:359-65.

7. Michelutti L, Falter H, Certossi S, Marcotte B, Mazzuchin A. Isolation and purification of creatine kinase conversion factor from human serum and its identification as carboxypeptidase N. Clin Biochem 1987; 20:21-9.

8. Billadello JJ, Fontanet HL, Strauss AW, Abendschein DR. Characterization of MB creatine kinase isoform conversion in vitro and in vivo in dogs. $\mathrm{J}$ Clin Invest 1989; 83:1037-43.

9. Prager NA, Suzuki T, Jaffe AS, Sobel BE, Abendschein DR. Nature and time course of generation of isoforms of creatine kinase-MB fraction in vivo. J Am Coll Cardiol 1992; 20:414-9.

10. Erdös EG, Wohler IM, Levine MI, Westermann MP. Carboxypeptidase in blood and other fluids: values in human blood in normal and pathological conditions. Clin Chim Acta 1965; $11: 39-43$. 
11. Levin Y, Skidgel RA, Erdös EG. Isolation and characterization of the subunits of human plasma carboxypeptidase $\mathrm{N}$ (kininase I). Proc Natl Acad Sci USA 1982; 79:4618-22.

12. Erdös EG, Skidgel RA. More on subforms of creatine kinaseMB. N Engl J Med 1995; 333:390.

13. Abendschein DR, Serota H, Plummer TH, Amiraian K, Strauss $\mathrm{AW}$, Sobel BE, et al. Conversion of MM creatine kinase isoforms in human plasma by carboxypeptidase N. J Lab Clin Med 1987; 110:798-806.

14. Pasternak RC, Braunwald E, Sobel BE. Acute myocardial infarction. In: Braunwald E, editor. Heart disease. Philadelphia: WB Saunders, 1988:1222-313.

15. Plummer TH, Kimmel MT. An improved spectrophotometric assay for human plasma carboxypeptidase N. Anal Biochem $1980 ; 108: 348-53$.

16. International Federation of Clinical Chemistry. IFCC methods for the measurement of catalytic concentration of enzymes; Part 7. IFCC method for creatine kinase (ATP : Creatine Nphosphotransferase, EC 2.7.3.2). IFCC recommendation. Clin Chim Acta 1990; 190:S4-S40; Eur J Clin Chem Clin Biochem $1991 ; 29: 435-56$.
17. Panteghini M. Serum isoforms of creatine kinase isoenzymes. Clin Biochem 1988; 21:211-8.

18. Puleo PR, Guadagno PA, Roberts R, Perryman MB. Sensitive, rapid assay of subforms of creatine kinase-MB in plasma. Clin Chem 1989; 35:1452-5.

19. Abendschein DR, Seacord LM, Nohara R, Sobel BS, Jaffe AS. Prompt detection of myocardial injury by assay of creatine kinase isoforms in initial plasma samples. Clin Cardiol 1988; 11:661-4.

20. Wu AHB. Creatine kinase-MM and MB isoforms. Lab Med $1992 ; 23: 303-5$.

21. Harker CC, Wu AHB. Early diagnosis of acute myocardial infarction (MI) upon initial hospital admission using CK-MB2 isoform analysis. Clin Chem 1990; 36:1128.

22. Panteghini M, Bonora R, Pagani F. An immunoinhibition assay for determination of creatine kinase isoforms in serum. Eur J Clin Chem Clin Biochem 1994; 32:383-9.

\section{Received September 10, 1996/January 6, 1997}

Corresponding author: Dr. ssa Martina Zaninotto, Servizio di Medicina di Laboratorio, Azienda Ospedaliera di Padova, Via Giustiniani 2, I-35128 Padova, Italy 
